\title{
Distribution of corneal thickness measured using optical coherence tomography in South African young adults
}

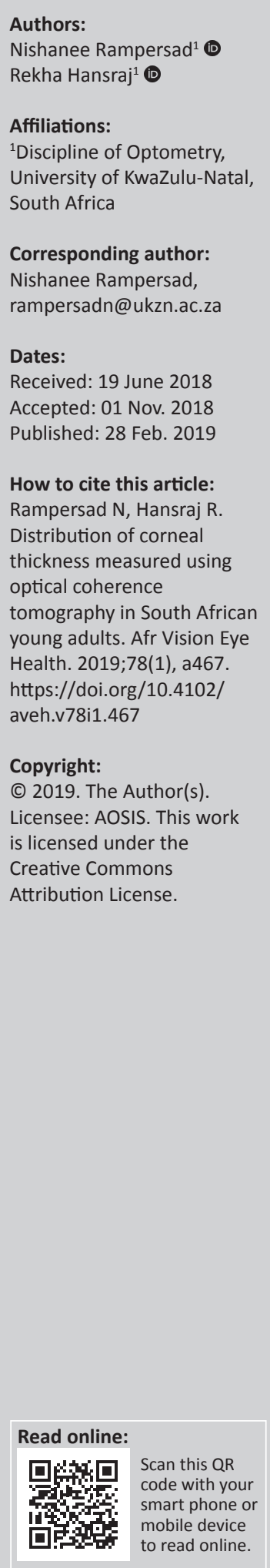

Background: Corneal thickness measurements have various diagnostic and therapeutic applications. Studies have reported on the distribution of corneal thickness measurements in Caucasian and Asian subpopulations with limited focus on African subpopulations.

Aim: The goal of this study was to examine the distribution of corneal thickness measured using optical coherence tomography in a South African young adult population.

Setting: The study was conducted at the eye clinic at the University of KwaZulu-Natal.

Methods: The study used a quantitative cross-sectional research design and participants were recruited using two-stage random sampling. Seven hundred participants consisting of 50\% South African blacks and 50\% South African Indians aged between 17 and 30 years were included. The sample included an equal distribution of male $(n=350)$ and female $(n=350)$ participants. Corneal thickness was measured using the Fourier-domain Optovue iVue100 optical coherence tomographer. As the data from the right and left eyes showed high levels of interocular symmetry, data from only the right eyes were analysed using descriptive and inferential statistics.

Results: The mean age of the sample was $20.42 \pm 1.80$ years. Corneal thickness measurements resembled Gaussian curves $(p \geq 0.095)$ and the mean central corneal thickness (CCT) was $501.91 \mu \mathrm{m}$. Corneal thickness at the thinnest point was $495.73 \mu \mathrm{m}$ and $1.23 \%$ thinner than the mean CCT measurement $(p<0.001)$. Males had slightly higher corneal thickness measurements than females but these differences $(0.35 \mu \mathrm{m}-3.93 \mu \mathrm{m})$ were not significant $(p \geq 0.137)$. Corneal thickness varied significantly with refractive error and was lowest in emmetropes followed by myopes and then hyperopes.

Conclusion: Corneal thickness measurements are normally distributed in South African young adults. The mean CCT is different from that reported in other populations and lower than the calibrated CCT measurement for Goldmann applanation tonometry. Eye care personnel should consider the characteristics of corneal thickness measurements and its implications on intraocular pressure measurements when examining South African individuals.

\section{Introduction}

Corneal thickness measurements have clinical importance in refractive surgery, ${ }^{1}$ contact lens wear, ${ }^{2}$ corneal disease ${ }^{3}$ and interpretation of intraocular pressure (IOP) measurements. ${ }^{4}$ Moreover, corneal thickness provides an indirect assessment of corneal physiology and hydration. ${ }^{5}$ Several contact and non-contact methods may be used to measure corneal thickness. ${ }^{6,7}$ Ultrasound pachymetry is a widely used method because of its low cost, portability and ease of use. ${ }^{8}$ Even though ultrasound pachymetry has demonstrated good repeatability, ${ }^{9,10}$ placement of the ultrasound probe is examiner dependent and contact with the corneal surface may result in superficial lesions, transmission of infections and inaccurate measurements. ${ }^{11}$

Optical coherence tomography (OCT) allows for non-contact scanning and imaging of biological structures. ${ }^{12,13}$ This method, first described in 1991, ${ }^{12}$ uses low-coherence interferometry and reflected near-infrared light to create high resolution cross-sectional images (tomograms). ${ }^{14}$ Since the first reported use of OCT to measure corneal thickness in $1994,{ }^{15}$ this method has undergone several improvements such as faster scanning speeds together with improved resolution ${ }^{16}$ and is being increasingly used to measure corneal thickness. ${ }^{9,17}$ Additionally, OCT devices are capable of pachymetry mapping that involves simultaneously measuring thickness across a wide area of the 
cornea. ${ }^{18}$ As a result, studies have reported on central ${ }^{19,20,21}$ and peripheral ${ }^{17,22}$ corneal thickness measurements using OCT devices. Moreover, it has been reported that corneal thickness measurements with OCT devices are accurate, ${ }^{16}$ comparable with ultrasound pachymetry ${ }^{9}$ as well as reliable and reproducible..$^{23,24,25}$

Previous studies that investigated the distribution of corneal thickness measurements in adult populations have had certain limitations. Firstly, most of these studies have involved predominantly Caucasian or Asian subpopulations s, $26,27,28,29,30^{2}$ with limited attention to African subpopulations. Racial variations in corneal thickness are well documented wherein higher measurements have been noted in Caucasian, Hispanic and Chinese populations compared with AfricanAmerican and Japanese populations. ${ }^{31,32}$ Secondly, the majority of studies ${ }^{19,27,30}$ have focused exclusively on central corneal thickness (CCT) measurements with limited attention to peripheral corneal thickness measurements that are important for surgeries and diseases that extend beyond the central cornea..$^{33,34}$ In addition, corneal thickness measurements are known to decrease with increasing age. ${ }^{20,35}$ In some studies, the influence of age on corneal thickness was not considered and it is likely that the results were biased in samples consisting of participants with wide age ranges. ${ }^{19,27,28}$ Finally, some studies have used ultrasound pachymetry devices, ${ }^{26,27,30}$ which have different operating principles and poorer repeatability when compared with OCT devices. ${ }^{25,36}$

As corneal thickness is influenced by demographic and/or environmental factors, ${ }^{37}$ it is necessary to understand the distribution of corneal thickness measurements in different populations. ${ }^{35}$ Little information is available on the distribution of corneal thickness measurements in a South African population as only one study has reported on the distribution of CCT measurements. ${ }^{38}$ Therefore, the purpose of this study was to examine the distribution of central and peripheral corneal thickness measured using OCT in a South African young adult population.

\section{Methodology}

The study employed a quantitative cross-sectional research design. Two-stage random sampling was used to recruit 700 participants (50\% blacks and 50\% Indians), aged between 17 years and 30 years, from the university student population.

All participants underwent a complete eye examination that included case history (ocular and medical), logarithm of the minimum angle of resolution (LogMAR) distance visual acuity, ophthalmoscopy, slit lamp biomicroscopy and noncontact tonometry using the Nidek NT 530P Tonopachy (Nidek Co LTD, United States). Autorefraction, using the Nidek AR-310A (Nidek Co LTD, United States), was performed on all participants and subsequently refined with subjective refraction to determine the refractive error. The subjective refraction was converted to a spherical equivalent (SE), which was calculated as the sphere power added to half the negative cylinder power. ${ }^{39}$ Based on the resulting SE, participants were classified as myopes (SE $<-0.50 \mathrm{D})$, hyperopes (SE $>+0.50 \mathrm{D})$ or emmetropes $(-0.50 \mathrm{D} \leq$ $\mathrm{SE} \leq+0.50 \mathrm{D})$. Participants with unaided or best corrected distance visual acuity worse than 0 LogMAR, IOP greater than $21 \mathrm{mmHg}$, previous history of ocular trauma and/or surgery, associated ocular and/or systemic conditions and currently on medication were excluded. Soft contact lens wear was discontinued for at least 3 weeks preceding data collection and none of the participants were rigid gaspermeable contact lens wearers.

The Fourier-domain Optovue iVue100 (Optovue, United States) optical coherence tomographer was used to measure corneal thickness. This OCT device has a scan rate of 25000 A-scans per second and uses light of wavelength $830 \mathrm{~nm}-850 \mathrm{~nm}$ with axial and transverse resolutions of $5 \mu \mathrm{m}$ and $15 \mu \mathrm{m}$ respectively. ${ }^{40}$ The iVue100 OCT device has a preprogrammed algorithm that defines the corneal epithelium as the anterior boundary and the corneal endothelium as the posterior boundary. ${ }^{40}$ Consequently, corneal thickness is automatically determined as the distance between the anterior and posterior boundaries. When capturing the corneal scans, the inbuilt internal fixation target was used while the real-time image of the participant's eye and corresponding corneal tomogram were monitored on a laptop screen. Corneal scans that were labelled as poor on the laptop screen or had scan quality indices of lower than 27 were repeated in accordance with the manufacturer's recommendations. ${ }^{40}$ All corneal scanning was performed after participants had been awake for at least 2 hours to minimise the influence of closed-eye corneal swelling on the corneal thickness measurements. ${ }^{41}$

The cornea pachymetry scan protocol in the iVue100 OCT device was used to determine the corneal thickness. This scan protocol, which comprises eight radial line scans of $6 \mathrm{~mm}$ length that consist of $1024 \mathrm{~A}$-scans each, ${ }^{40}$ produces a $6 \mathrm{~mm} \times 6 \mathrm{~mm}$ pachymetry map (Figure 1 ). The pachymetry map, which displays the average corneal thickness, is divided by rings into three corneal sections (central, paracentral and peripheral). The CCT is displayed as the average thickness in the central 2-mm ring. The paracentral and peripheral cornea, of 5-mm and 6-mm diameter, are denoted by the middle and outermost rings respectively. Moreover, the paracentral and peripheral cornea are further divided into eight zones (superior, superior-temporal, temporal, inferior-temporal, inferior, inferior-nasal, nasal and superior-nasal) by octants. The average thickness in the different corneal sections comprising 17 zones are displayed accordingly in the corneal pachymetry map using a false-colour display (Figure 1). The iVue100 OCT device also determines the corneal thickness at the thinnest point (minimum) and displays its mean value in the pachymetry assessment box and location with a blue asterisk on the corneal pachymetry map ${ }^{40}$ (Figure 1). In this study, the average paracentral corneal thickness (ParaCT) and average peripheral corneal thickness (PeriCT) were computed as the average of the four cardinal quadrants (superior, inferior, nasal and temporal) therein. 


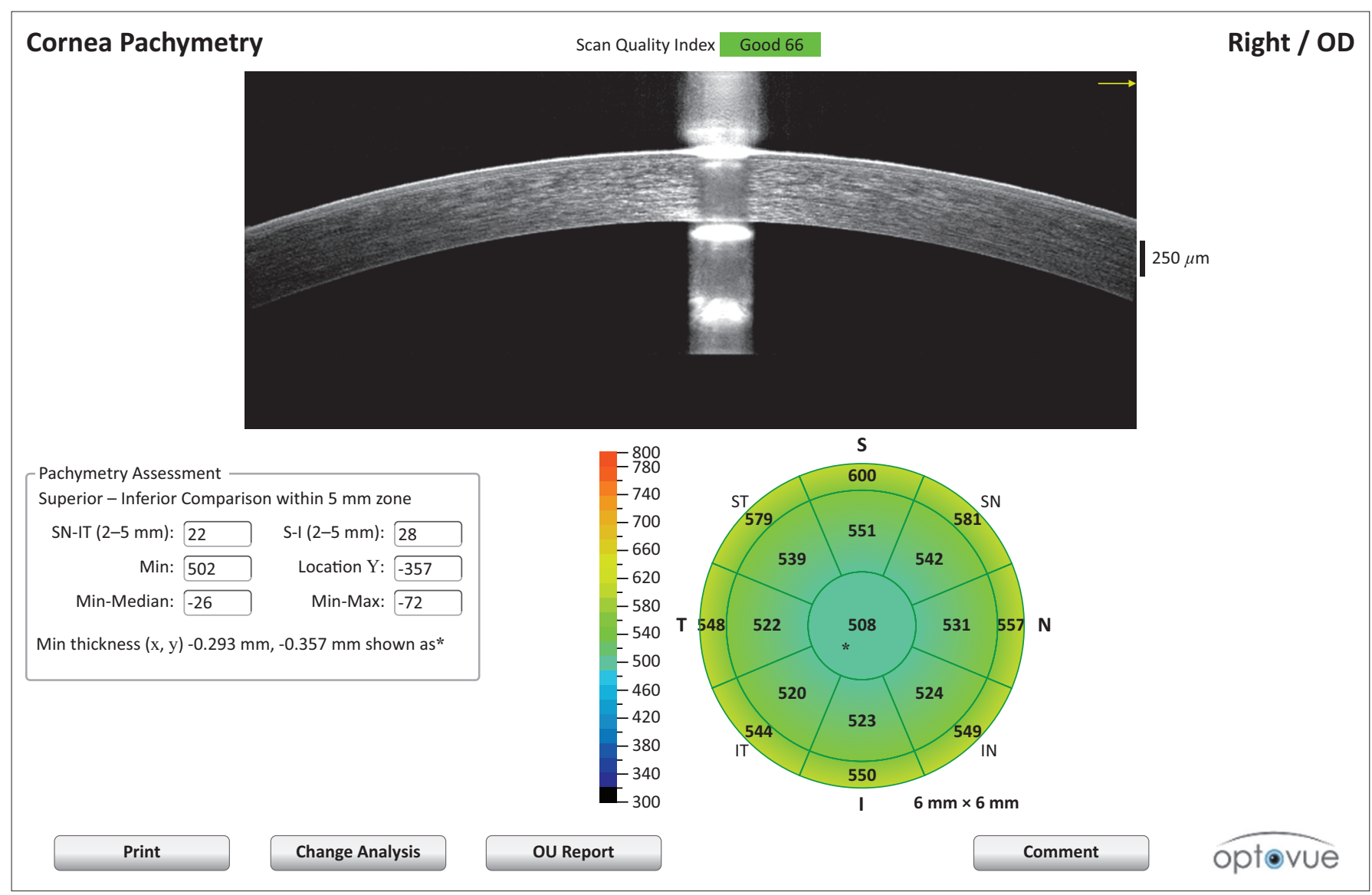

Source: Adapted screen shot of the output screen with the iVue 100 OCT device.

S, superior; SN, superior-nasal; N, nasal; IN, inferior-nasal; I, inferior; IT, inferior-temporal; T, temporal; ST, superior-temporal.

FIGURE 1: Corneal pachymetry map showing corneal tomogram (top), pachymetry assessment box (bottom left) and average corneal thickness in the centre and each zone of the paracentral and peripheral cornea (bottom right).

Studies have shown that time-domain ${ }^{23,24}$ and Fourierdomain ${ }^{24,25}$ OCT devices are reliable for repeated measurements of corneal thickness. The non-contact Nidek NT 530P Tonopachy is a reliable tonometer when compared with the clinical gold standard Goldmann applanation tonometer. ${ }^{42}$ The method used to determine and classify the SE in this study has been used previously. ${ }^{19,43}$ All data collection procedures were performed by one researcher to ensure standardisation of testing procedures and recording of results. Three consecutive measurements for corneal thickness were taken and averages computed. The clinical equipment and environment were kept constant throughout the data collection period.

Data were captured and analysed with the Statistical Package for Social Sciences version 25. Interocular symmetry was assessed using the intraclass correlation coefficient (ICC). ${ }^{44}$ The Shapiro-Wilk's test, graphical inspection of histograms and measures of skewness as well as kurtosis were used to assess the distribution of corneal thickness measurements. Corneal thickness measurements in the different zones are summarised as mean \pm standard deviation (SD), median and 95\% confidence intervals in microns. Gender differences in corneal thickness and differences in the three corneal sections were assessed with the independent and dependent sample $t$-tests respectively.
One-way analysis of variance (ANOVA) was performed to assess differences in corneal thickness among myopes, hyperopes and emmetropes. A probability $(p)$ value of 0.05 or less was considered statistically significant.

\section{Ethical considerations}

The study (reference number BE 289/12) was approved by the Biomedical Research and Ethics Committee of the University of KwaZulu-Natal. All ethical guidelines, in accordance with the Declaration of Helsinki, were adhered to during the study and all participants provided written informed consent after a discussion of the study nature and procedures therein.

\section{Results}

The study sample $(N=700)$ consisted of an equal distribution of male $(n=350)$ and female $(n=350)$ participants. The mean age of participants was $20.42 \pm 1.80$ years and ranged from 17 to 29 years. There was no significant difference in mean age between the male $(20.57 \pm 1.93)$ and female $(20.28 \pm 1.65)$ participants $(p=0.093)$. The preliminary statistical analysis showed high levels of interocular symmetry for corneal thickness measurements at the centre (ICC of 0.993), thinnest point (ICC of 0.994), paracentral (ICCs $\geq 0.983$ ) and peripheral (ICCs $\geq 0.975$ ) quadrants. Data from only the right eyes of the 
TABLE 1: Distribution of corneal thickness measurements $(\mu \mathrm{m})$ in the different zones of the right eye for the entire sample $(N=700)$.

\begin{tabular}{|c|c|c|c|c|c|c|c|}
\hline Corneal variable & Mean & SD & Median & $\mathrm{Cl}$ & Skewness & Kurtosis & $\mathrm{S}-\mathrm{W}(p)$ \\
\hline CCT & 501.91 & 33.74 & 503 & {$[499.40 ; 504.41]$} & 0.09 & -0.09 & 0.193 \\
\hline Minimum & 495.73 & 33.89 & 496 & [493.21; 498.24] & 0.09 & -0.12 & 0.175 \\
\hline Paracentral superior & 534.24 & 35.15 & 534 & {$[531.64 ; 536.85]$} & 0.07 & -0.07 & 0.215 \\
\hline Paracentral inferior & 513.21 & 35.15 & 514 & {$[510.61 ; 515.82]$} & 0.12 & -0.05 & 0.114 \\
\hline Paracentral nasal & 522.92 & 34.34 & 523 & {$[520.37 ; 525.47]$} & 0.12 & -0.03 & 0.314 \\
\hline Paracentral temporal & 513.85 & 34.94 & 514 & {$[511.26 ; 516.44]$} & 0.10 & -0.12 & 0.157 \\
\hline Peripheral superior & 567.64 & 37.24 & 569 & {$[564.87 ; 570.40]$} & 0.10 & -0.04 & 0.234 \\
\hline Peripheral inferior & 536.66 & 36.87 & 537 & {$[533.93 ; 539.40]$} & 0.14 & -0.03 & 0.095 \\
\hline Peripheral nasal & 548.86 & 35.71 & 549 & {$[546.21 ; 551.51]$} & 0.15 & -0.01 & 0.160 \\
\hline Peripheral temporal & 534.10 & 35.80 & 535 & {$[531.45 ; 536.76]$} & 0.11 & -0.05 & 0.221 \\
\hline
\end{tabular}

CCT, central corneal thickness; SD, standard deviation; $\mathrm{Cl}$, confidence interval (95\% of means); S-W, Shapiro-Wilk's test for normality ( $p$-values are indicated).

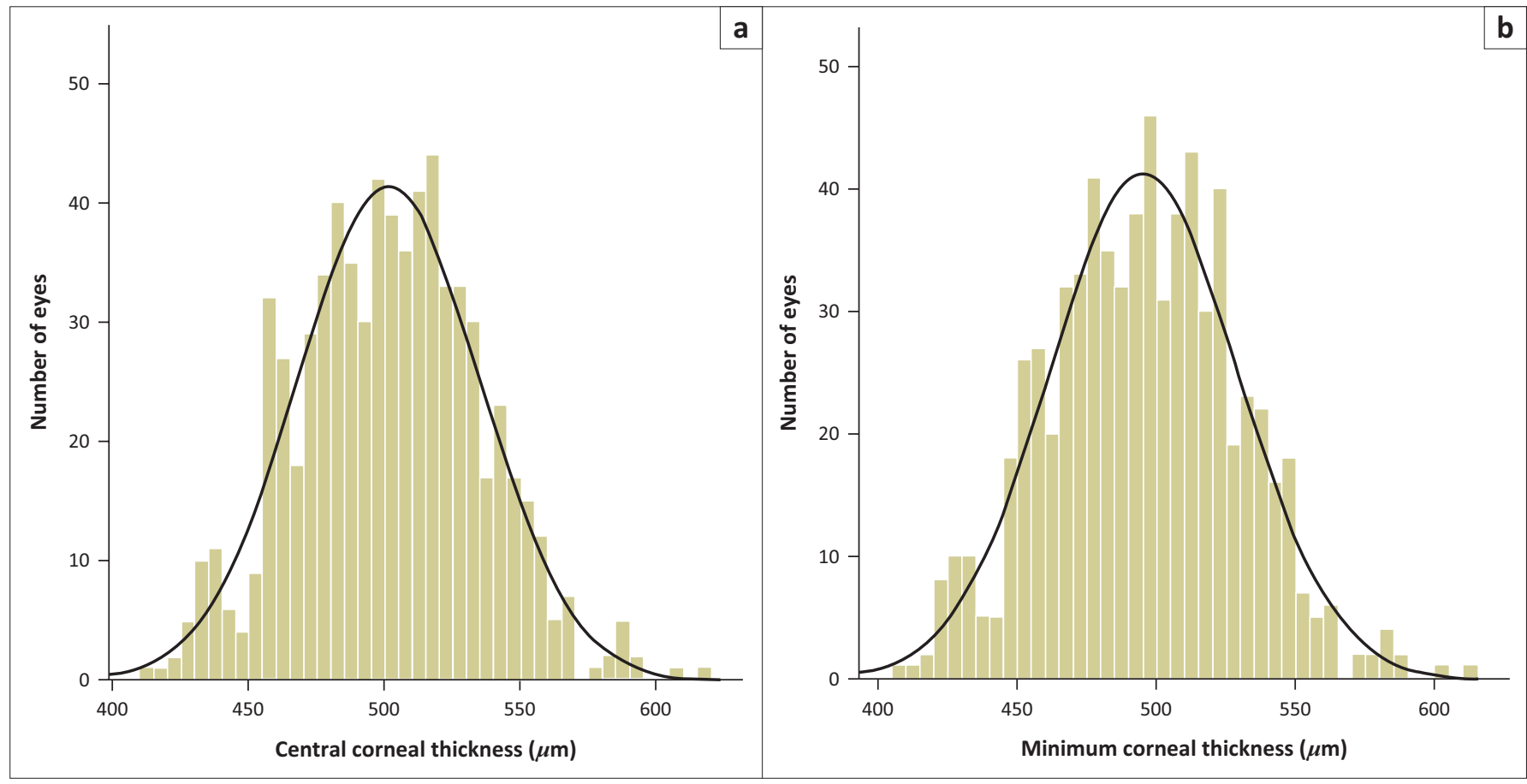

FIGURE 2: Distribution of central corneal thickness (a) and minimum corneal thickness (b) $(\mu \mathrm{m})$ in the right eyes of young adult participants $(N=700)$, aged $17-30$ years

700 participants were analysed because of the high levels of interocular symmetry.

Table 1 summarises the distribution of corneal thickness measurements for the centre and thinnest point as well as the four paracentral and peripheral quadrants. According to the Shapiro-Wilk test, the corneal thickness measurements were normally distributed in all zones (all $p$-values $\geq 0.095$ ). Moreover, histograms for the corneal thickness measurements resembled Gaussian curves in all zones (Figures 2, 3 and 4) with skewness and kurtosis ranges of 0.07 to 0.15 and -0.01 to -0.12 respectively (Table 1 ). The mean CCT measurement was $501.91 \pm 33.74 \mu \mathrm{m}$ and ranged from $413 \mu \mathrm{m}$ to $618 \mu \mathrm{m}$. Only two participants presented with mean CCT measurements that were greater than $600 \mu \mathrm{m}$ whereas $47 \%$ of participants $(n=326)$ had mean CCT measurements that were less than $500 \mu \mathrm{m}$. The mean corneal thickness at the thinnest point was $495.73 \pm$ $33.89 \mu \mathrm{m}$, which is equivalent to $1.23 \%$ thinner than the mean CCT $(p<0.001)$. The difference between the CCT and minimum corneal thickness measurements ranged from
$2 \mu \mathrm{m}$ to $31 \mu \mathrm{m}$ with a mean difference of $6.18 \mu \mathrm{m}$. In $95 \%$ of participants $(n=668)$, the thickness difference between these two points was $9 \mu \mathrm{m}$ or lower. In the majority of participants $(n=659)$, the thinnest corneal point was located in the central zone and then in the inferior temporal $(n=29)$, temporal $(n=6)$ or inferior $(n=6)$ zones.

The CCT measurement was significantly thinner than the mean corneal thickness measurement for each quadrant in the paracentral and peripheral cornea $(p<0.001)$. Moreover, the lowest SD was noted for the CCT measurement and increased as the distance away from the corneal centre increased (Table 1). The average ParaCT and PeriCT were $521.06 \pm 34.56 \mu \mathrm{m}$ and $546.82 \pm 35.71 \mu \mathrm{m}$ respectively. Not surprisingly, the mean CCT measurement was significantly thinner than the average ParaCT (mean difference of $19.15 \mu \mathrm{m}, p<0.001$ ) and PeriCT (mean difference of $44.91 \mu \mathrm{m}, p<0.001)$ measurements. For both the paracentral and peripheral cornea, the superior quadrant was the thickest while the inferior and temporal quadrants were thinnest in the paracentral and peripheral cornea respectively. Similar corneal thickness measurements, 

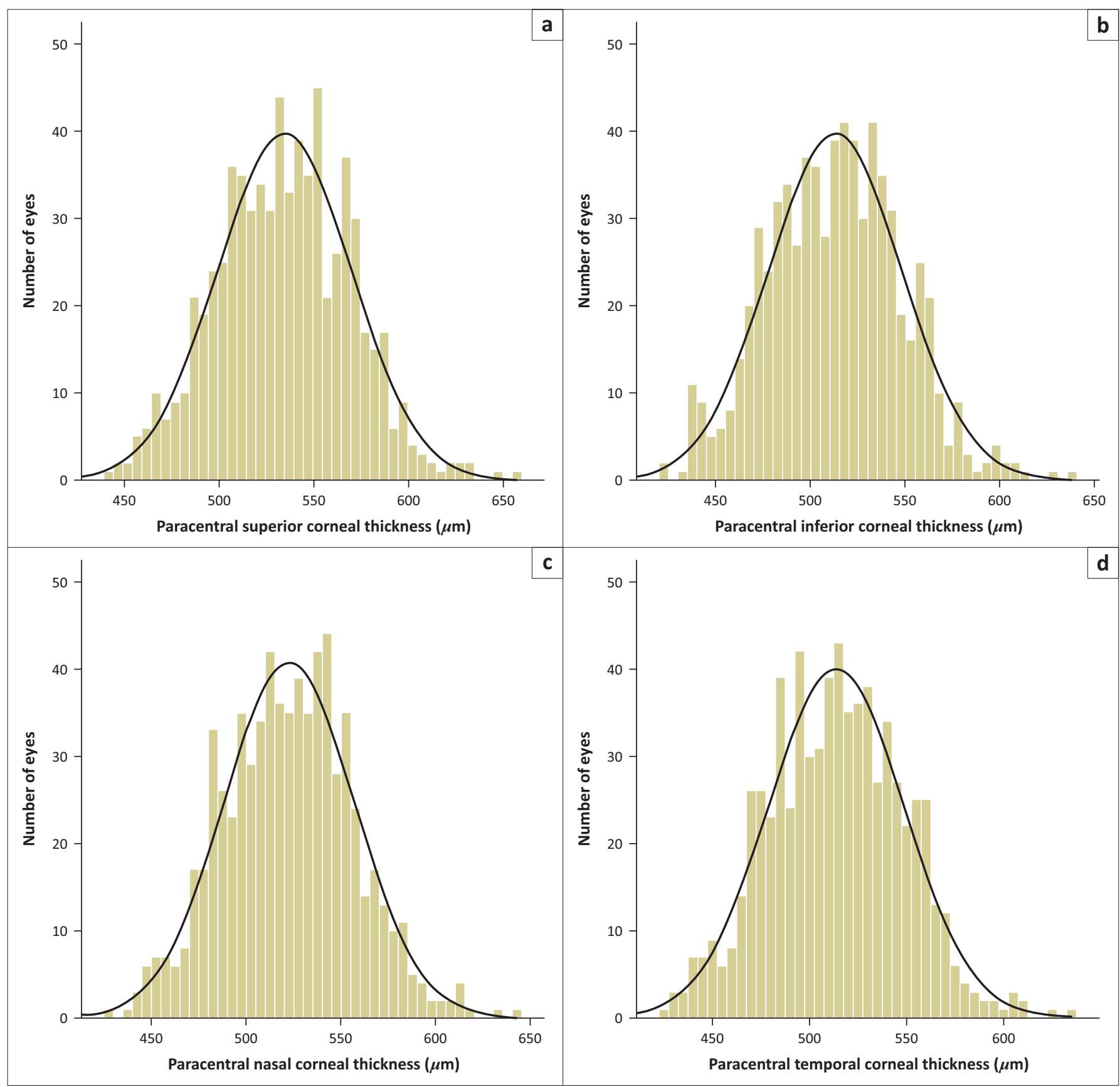

FIGURE 3: Distribution of paracentral superior (a), inferior (b), nasal (c) and temporal (d) corneal thickness $(\mu \mathrm{m})$ in the right eyes of young adult participants $(N=700)$, aged $17-30$ years.

which were less than $3 \mu \mathrm{m}$, were found for the inferior and temporal quadrants of the paracentral and peripheral cornea (Table 1). Overall, corneal thickness measurements were asymmetrical in the paracentral and peripheral cornea wherein higher corneal thickness measurements were noted in the superior and nasal quadrants compared with the inferior and temporal quadrants (Table 1).

Table 2 presents the corneal thickness measurements stratified for gender and refractive error. Even though males had slightly higher mean corneal thickness measurements than females for all zones (range, $0.35 \mu \mathrm{m}$ in the peripheral nasal zone to $3.93 \mu \mathrm{m}$ in the paracentral temporal zone), these gender differences were not statistically significant $(p \geq 0.137)$. The mean CCT in males and females were $503.67 \pm 34.58 \mu \mathrm{m}$ and $500.14 \pm 32.83 \mu \mathrm{m}$ respectively $(p=0.166)$. For both males and females, corneal thickness was highest in the superior quadrant of the paracentral and peripheral cornea. For both male and female participants, the paracentral inferior and peripheral temporal quadrants showed the lowest corneal thickness measurements (Table 2). The corneal thickness measurements were significantly different in all zones for the three refractive error groups $(p \leq 0.001)$, wherein lowest measurements were noted for emmetropes followed by myopes and then hyperopes (Table 2). The mean CCT was $498.89 \mu \mathrm{m}, 508.44 \mu \mathrm{m}$ and $535.25 \mu \mathrm{m}$ in emmetropes, myopes and hyperopes respectively $(p<0.001)$. A post-hoc analysis (Gabriel) showed that emmetropes had significantly thinner corneal thickness measurements than myopes in all zones 


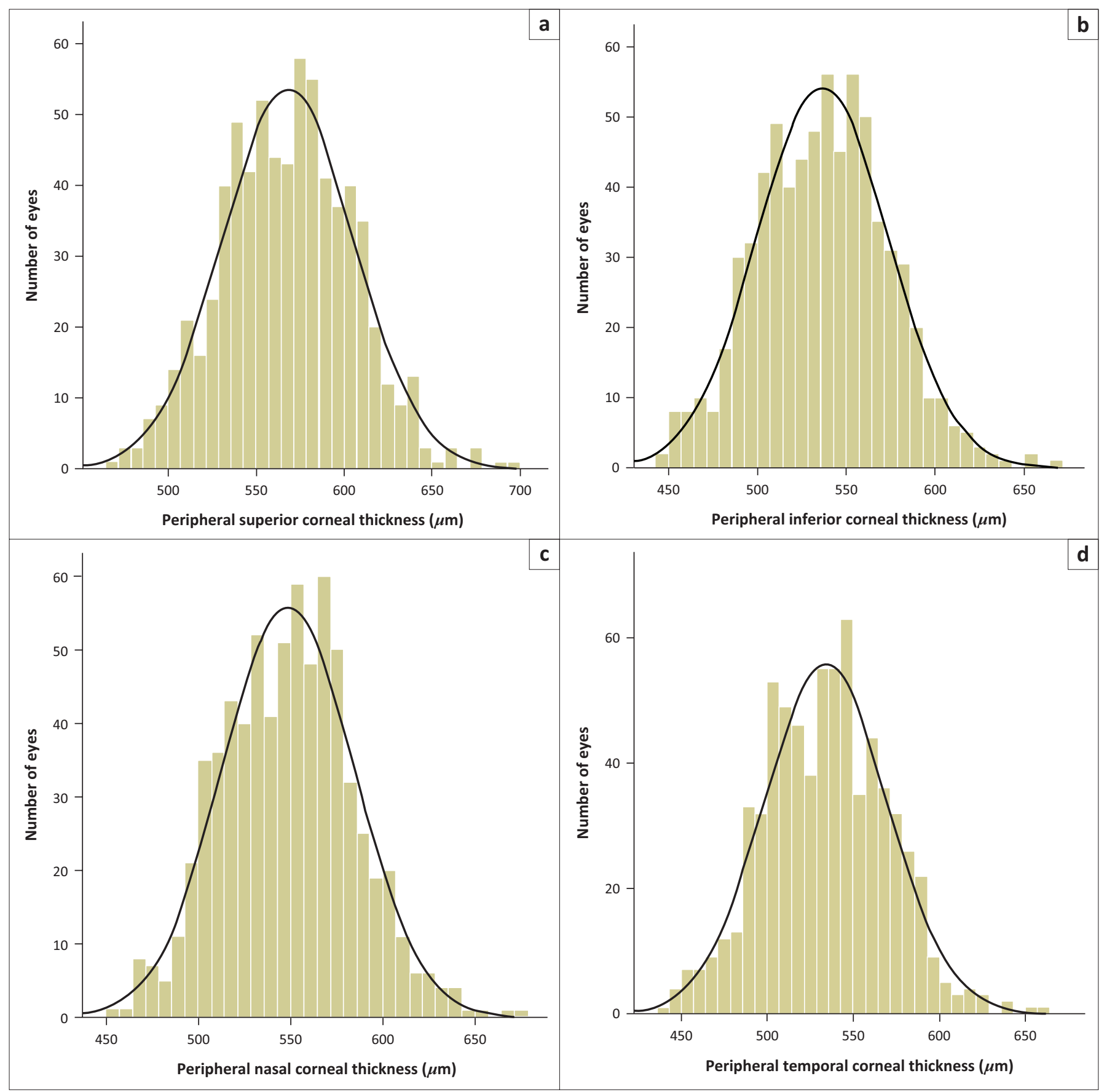

FIGURE 4: Distribution of peripheral superior (a), inferior (b), nasal (c) and temporal (d) corneal thickness ( $\mu \mathrm{m}$ ) in the right eyes of young adult participants ( $N=700)$, aged $17-30$ years.

( $p \leq 0.002$ ). Even though myopes had thinner corneal thickness measurements than hyperopes for all zones, these thickness differences failed to reach statistical significance ( $p \geq 0.115$ ). It is important to note that as the sample included very few hyperopes $(n=4)$, one should be cautious with interpretation of any results relating to the sample of hyperopes in this study.

\section{Discussion}

In this study, the histograms and normality indices suggested that corneal thickness measurements via OCT in a South African young adult population were normally distributed. This finding is in agreement with studies involving Chinese, ${ }^{29}$
Iranian, ${ }^{45}$ Puerto Rican, ${ }^{46}$ New Zealand ${ }^{47}$ and Korean ${ }^{30}$ populations that have also reported normal distributions for central $29,30,45,46,47$ and peripheral ${ }^{29,45}$ corneal thickness measurements. Even the corneal thickness measurements at the thinnest point were normally distributed, as has been reported previously. ${ }^{48}$ It has been theorised that most biological variables, in a general population, are normally distributed. ${ }^{49,50}$ Consequently, the finding of corneal thickness measurements resembling Gaussian curves is not unexpected as they are similar to other biological characteristics. ${ }^{29,37}$ It is also possible that the inclusion of only healthy participants without any ocular diseases and/or anomalies in this and other such studies $^{29,35,46}$ may further account for the observation of normally distributed corneal thickness measurements. 
TABLE 2: Corneal thickness $(\mu \mathrm{m})$ in each zone segmented by gender and refractive error indicated with means and standard deviations.

\begin{tabular}{|c|c|c|c|c|c|c|c|c|c|c|}
\hline \multirow[t]{3}{*}{ Corneal variable } & \multicolumn{4}{|c|}{ Gender } & \multicolumn{6}{|c|}{ Refractive error } \\
\hline & \multicolumn{2}{|c|}{$\begin{array}{c}\text { Male } \\
(n=350)\end{array}$} & \multicolumn{2}{|c|}{$\begin{array}{c}\text { Female } \\
(n=350)\end{array}$} & \multicolumn{2}{|c|}{$\begin{array}{l}\text { Emmetropes } \\
\qquad(n=490)\end{array}$} & \multicolumn{2}{|c|}{$\begin{array}{l}\text { Myopes } \\
(n=206)\end{array}$} & \multicolumn{2}{|c|}{$\begin{array}{l}\text { Hyperopes } \dagger \\
\quad(n=4)\end{array}$} \\
\hline & Mean & SD & Mean & SD & Mean & SD & Mean & SD & Mean & SD \\
\hline CCT & 503.67 & 34.58 & 500.14 & 32.83 & 498.89 & $33.13 *$ & 508.44 & 33.40 & 535.25 & 64.12 \\
\hline Minimum & 497.45 & 34.76 & 494.01 & 32.96 & 492.79 & $33.15^{*}$ & 502.11 & 33.96 & 527.25 & 64.59 \\
\hline Paracentral superior & 535.55 & 35.86 & 532.94 & 34.43 & 530.77 & $34.41 *$ & 541.84 & 34.69 & 568.75 & 71.97 \\
\hline Paracentral inferior & 514.75 & 36.06 & 511.68 & 34.21 & 509.95 & $34.35 *$ & 520.43 & 35.04 & 542.00 & 72.40 \\
\hline Paracentral nasal & 523.77 & 35.20 & 522.07 & 33.49 & 519.85 & $33.62 *$ & 529.55 & 34.09 & 557.75 & 70.36 \\
\hline Paracentral temporal & 515.82 & 35.58 & 511.89 & 34.22 & 510.36 & $34.19 *$ & 521.54 & 34.60 & 546.00 & 68.54 \\
\hline Peripheral superior & 567.91 & 37.75 & 567.37 & 36.77 & 564.13 & $36.47^{*}$ & 575.32 & 36.83 & 601.25 & 77.75 \\
\hline Peripheral inferior & 537.88 & 37.50 & 535.44 & 36.24 & 532.91 & $36.18^{*}$ & 545.10 & 36.19 & 561.50 & 76.51 \\
\hline Peripheral nasal & 549.04 & 36.28 & 548.69 & 35.17 & 545.49 & $34.94 *$ & 556.22 & 35.40 & 583.75 & 72.68 \\
\hline Peripheral temporal & 535.54 & 36.23 & 532.67 & 35.35 & 530.21 & $34.93 *$ & 542.72 & 35.33 & 567.5 & 72.92 \\
\hline
\end{tabular}

$\mathrm{CCT}$, central corneal thickness; SD, standard deviation.

$*, p$-value $\leq 0.05$, one-way analysis of variance (ANOVA) test.

$\dagger$, Owing to the small number of hyperopes $(n=4)$, one should interpret any comparisons that involve this sample with caution.

The corneal thickness measurements for the right and left eyes, obtained using the iVue100 OCT device, showed high levels of interocular symmetry with ICCs greater than 0.974 . These results are not surprising because ocular variable measurements in the two eyes of the same individual are related in the absence of any anomalies. ${ }^{44}$ This may be owing to the inherent structural similarities between the right and left eyes. ${ }^{48,51}$ Moreover, the trend of high interocular symmetry for corneal thickness measurements is consistent with the findings of other studies that used ultrasound pachymetry, ${ }^{26}$ Scheimpflug photography, ${ }^{29}$ Orbscan $^{43}$ and OCT ${ }^{48}$ devices. In contrast, an early study by Foster et al. ${ }^{28}$ reported a significant CCT interocular difference of $\sim 20 \mu \mathrm{m}$. In their study, Foster et al..$^{28}$ used an outmoded older-type optical pachymeter to measure corneal thickness, and perhaps systematic errors because of misalignment of the optical pachymeter with the corneal surface may account for the large interocular difference noted. ${ }^{28,47}$

The mean CCT found in this study $(501.91 \mu \mathrm{m})$ is considerably lower compared with previous studies involving young adult samples. Sanchis-Gimeno et al. ${ }^{52}$ used an Orbscan device and reported a mean CCT of $554 \mu \mathrm{m}$ in 1000 adults aged between 20 and 30 years. In a study consisting of 1669 Chinese adults with mean age of $23.8 \pm 5.9$ years, $\mathrm{Li}$ et al..$^{53}$ reported a mean CCT of $548.58 \mu \mathrm{m}$ using ultrasound pachymetry. An early study ${ }^{54}$ reported a mean CCT of $575 \mu \mathrm{m}$ with ultrasound pachymetry in 151 Asian adults with a mean age of $28.6 \pm 11.3$ years. More recently Mohd-Ali et al..$^{55}$ noted a mean CCT of $596.03 \mu \mathrm{m}$ in 84 Asian adults with a mean age of $21.42 \pm 1.47$ years. A study involving 200 South African young adults, with a mean age of $20.1 \pm 1.6$ years, reported a mean CCT measurement of $519.5 \mu \mathrm{m}$ using a Scheimpflug photography device. ${ }^{38}$ Prakash et al.$^{48}$ used a Fourier-domain OCT device and reported a mean CCT measurement of $517.3 \mu \mathrm{m}$ in 100 Indian adults with a mean age of $25.4 \pm$ 1.8 years. The discrepancy in mean CCT measurements obtained in this study compared with other studies involving young adult samples may be attributed to additional factors that affect corneal thickness measurements including ethnicity, differences in sample sizes and gender distributions as well as ocular variables including corneal curvature, IOP and refractive error. ${ }^{7,31,33,54}$ It is also likely that the different study methodologies, particularly the method used to measure corneal thickness, may also account for the variation in mean CCT measurements, as different pachymeters use varying operating principles to measure corneal thickness. ${ }^{7,33}$

Knowledge of the mean CCT measurement is important for various clinical and surgical applications. ${ }^{7}$ It is well recognised that CCT measurements influence IOP measurements, wherein the latter is underestimated in thinner central corneas and overestimated in thicker central corneas. ${ }^{19}$ Goldmann applanation tonometry, which is the clinical gold standard for measuring IOP, is calibrated using a theoretical assumption of $520 \mu \mathrm{m}$ for the CCT measurement. ${ }^{56}$ The mean CCT measurement in this study is lower than this calibrated theoretical assumption, which suggests that IOP measurements using Goldmann applanation tonometry may be underestimated in young South African adults and that eye care personnel should exercise more attention when interpreting IOP measurements in these individuals. The CCT measurement is also an important consideration for laser in situ keratomileusis, as it is not usually performed in individuals with CCT measurements lower than $500 \mu \mathrm{m} \cdot{ }^{57}$ This implies that just under half of the participants in this study may not be eligible for laser in situ keratomileusis if a cut-off value of $500 \mu \mathrm{m}$ is used.

According to the meta-analysis by Doughty and Zaman, ${ }^{33}$ a mean CCT measurement greater than $600 \mu \mathrm{m}$ is observed in less than $5 \%$ of the general population. In the present study, only a small proportion of participants (less than 1\%) had mean CCT measurements greater than $600 \mu \mathrm{m}$. This is consistent with the reports of other studies that noted approximately $3 \%$ of their healthy non-glaucomatous participants had mean CCT measurements greater than $600 \mu \mathrm{m} .{ }^{58,59}$ In contrast, other studies ${ }^{31,32}$ that included participants with corneal anomalies and ocular hypertension have reported higher percentages of participants with mean CCT measurements greater than $600 \mu \mathrm{m}$. For example, Brandt et al. $^{32}$ reported that approximately one out of every four participants $(24 \%)$ in the Ocular Hypertension Treatment Study (OHTS) had mean CCT measurements greater than 
$600 \mu \mathrm{m}$, which may be owing to their sample consisting of only individuals with ocular hypertension. Aghaian et al. ${ }^{31}$ included both normal participants and participants with various glaucoma disorders (primary open-angle, chronic angle-closure, normal tension, ocular hypertension and pseudoexfoliation) in their sample and reported that $7.2 \%$ of their participants had mean CCT measurements greater than or equal to $600 \mu \mathrm{m}$.

The CCT measurement was significantly thinner than the mean corneal thickness for each quadrant in the paracentral and peripheral cornea, which is in agreement with the findings of other studies. ${ }^{52,60}$ In the absence of ocular diseases and/or anomalies, there is a progressive increase in corneal thickness measurements from the centre to the periphery. ${ }^{52}$ This increase in corneal thickness measurements towards the periphery has been noted in studies involving paediatric, ${ }^{61}$ young adult ${ }^{52,55}$ and middle-aged to elderly adult ${ }^{35,45,60}$ samples. It is theorised that the increase in the number of collagen fibrils in the peripheral stroma compared with the central stroma accounts for the increasing thickness towards the corneal periphery. ${ }^{62}$ It is also speculated that apart from the stroma, the change in thickness of Bowman's layer towards the corneal periphery also contributes to the normal thickening of the cornea. ${ }^{63}$

Corneal thickness measurements beyond the central cornea (peripheral corneal thickness) are not often measured despite their importance in surgeries and diseases that involve these areas. For example, knowledge of the peripheral cornea may help to ensure a better match between the host and donor corneas in penetrating and/or deep anterior lamellar keratoplasties. ${ }^{16,64}$ In this study, corneal thickness measurements beyond the central cornea were asymmetric, which is consistent with the literature concerning peripheral corneal thickness wherein varying corneal thickness measurements have been noted. ${ }^{33,43,64}$ Moreover, the superior and nasal quadrants were thicker than the inferior and temporal quadrants for both the paracentral and peripheral cornea, as has been reported previously. ${ }^{11,35,45,64}$

In the present study, the superior quadrant had the largest corneal thickness measurement for both the paracentral and peripheral cornea. Other studies that have used varying noncontact pachymetry devices including Scheimpflug photography, ${ }^{11,29,45}$ slit-scanning topography ${ }^{35}$ and OCT ${ }^{17,22,65}$ have reported the same trend. The precise reason for the superior quadrant being the thickest is not readily explained. However, it is speculated that the superior corneal thickness is highest owing to chronic hypoxia induced by the upper eyelid that partially covers this corneal area in an open-eye state. ${ }^{66}$

In the present study, corneal thickness was lowest in the inferior and temporal quadrants of the paracentral and peripheral cornea respectively. The thickness difference between the inferior and temporal quadrants of the paracentral and peripheral cornea was less than $1 \mu \mathrm{m}$ and
$3 \mu \mathrm{m}$ respectively. Early studies, particularly with ultrasound pachymetry, considered the CCT measurement to be the thinnest point on the cornea. ${ }^{22,67}$ However, with technological advancements and pachymetry mapping, it is now being recognised that the thinnest point on the cornea lies most often infero-temporal to the CCT.,35 The position of the thinnest point lying inferior temporal to the CCT may account for the displacement of the corneal apex in keratoconus and position of the development of corneal ectasia post-laser in situ keratomileusis. ${ }^{68,69}$

In this study, the mean minimum corneal thickness measurement was $495.73 \mu \mathrm{m}$. This value is considerably smaller compared with the mean minimum corneal thickness measurements reported in other studies involving Iranian $(526 \mu \mathrm{m}-551 \mu \mathrm{m}),{ }^{35,45}$ Chinese $(528 \mu \mathrm{m}-548 \mu \mathrm{m}),{ }^{29,65}$ German $(535 \mu \mathrm{m}-578 \mu \mathrm{m})^{6,60}$ and American $(542 \mu \mathrm{m})^{17}$ samples. Although the mean minimum corneal thickness measurement was considerably lower, the SD associated with this measurement of $33.89 \mu \mathrm{m}$ is similar to that reported in previous studies. ${ }^{6,11,22,29,45}$ Not surprisingly, the minimum corneal thickness measurement was the lowest compared with the CCT and corneal thickness measurements in the different zones of the paracentral and peripheral cornea. The mean thickness difference between the minimum corneal thickness and CCT measurements was $6.18 \mu \mathrm{m}$, which is comparable to the values reported by Ashwin et al. ${ }^{67}(6.0 \mu \mathrm{m})$ and Randelman et al. ${ }^{17}(7.8 \mu \mathrm{m})$. In contrast, Hashemi et al. ${ }^{45}$ and Zheng et al. ${ }^{29}$ reported smaller thickness differences of $3.23 \mu \mathrm{m}$ and $3.24 \mu \mathrm{m}$, respectively, although their ranges of differences, being $0 \mu \mathrm{m}-105 \mu \mathrm{m}$ and $0 \mu \mathrm{m}-66 \mu \mathrm{m}$, respectively, were much wider than that found in the present study $(2 \mu \mathrm{m}-31 \mu \mathrm{m})$.

The minimum corneal thickness was $1.23 \%$ thinner than the CCT measurement, which is comparable to the percentage differences between these two points of $0.78 \%-2.80 \%$ reported in other studies. ${ }^{6,22,43}$ For the majority of participants $(95 \%)$, the thickness differences between the minimum corneal thickness and CCT measurements was $9 \mu \mathrm{m}$ or lower. The small extent of this difference implies that few participants had unusually low measurements at the thinnest point on the cornea and this may be owing to the inclusion of only healthy participants in the sample. This suggests that even though the CCT and minimum corneal thickness are important points for research and analysis, the difference in their thicknesses and location may not have clinical significance in the planning of refractive surgery for normal healthy individuals. ${ }^{11}$

The relationship between gender and corneal thickness measurements is inconsistent as there are contradictory reports in the literature. Some studies have reported higher corneal thickness measurements in males, ${ }^{5,19}$ whereas others have reported the opposite trend with higher measurements in females. ${ }^{27,35,64}$ In agreement with the former group of studies, this study noted higher corneal thickness values in males. Despite this observation and an equal distribution of 
male and female participants in the sample, these gender differences in corneal thickness measurements failed to reach statistical significance, which corroborates the findings of other studies. ${ }^{35,52,64}$ In contrast, Hahn et al. ${ }^{5}$ reported a statistically significant gender difference of $4.6 \mu \mathrm{m}$ in a study involving 1578 Latino individuals. However, the researchers concluded that this gender difference was unlikely to be clinically relevant owing to its low magnitude. ${ }^{5}$

The influence of refractive error on corneal thickness measurements, particularly the CCT, has been investigated previously but there is no agreement regarding this relationship. In the present study, statistically significant differences for the central and peripheral corneal thickness measurements were found among the three refractive error groups. The mean CCT measurement was thinnest in emmetropes $(\sim 499 \mu \mathrm{m})$ followed by myopes $(\sim 508 \mu \mathrm{m})$ and hyperopes $(\sim 535 \mu \mathrm{m})$, but this comparison should be interpreted with caution as there were very few participants with hyperopia $(n=4)$. Overall, the majority of studies have reported higher corneal thickness measurements in hyperopes compared with emmetropes and myopes. ${ }^{45,70,71,72}$ This suggests that the trend observed in this study is consistent with the pattern in the literature albeit that the sample consisted of only a few hyperopes $(n=4)$. There is little consensus in the literature related to which refractive error group has the lowest CCT measurements. Some studies have reported thinnest CCT measurements in myopes, ${ }^{71,72}$ whereas others have reported thinnest measurements in emmetropes. ${ }^{70,73}$ This lack of agreement and variation may be explained by the use of different methods to determine and subsequently classify refractive error, which compounds the comparison of results across studies.

Strengths of this study include the use of a large sample of young healthy black and Indian adults with an equal gender distribution and narrow age range. Corneal thickness was measured using a Fourier-domain OCT device with a standardised protocol and internal fixation target to minimise the effect of off-centre fixation, which may result in erroneous measurements. Limitations of this study include the narrow age range of the sample, which suggests that the study results must be interpreted with caution when generalised to younger and older South African individuals. Moreover, the relationship between age and corneal thickness could not be assessed owing to the narrow age range of participants. The sample also consisted of a small proportion of participants with hyperopia. Therefore, it is recommended that participants with wider age ranges and hyperopia, possibly determined as $\mathrm{SE} \geq+0.25 \mathrm{D}$, be included in future studies.

\section{Conclusion}

The central and peripheral corneal thickness measurements, obtained using OCT, in a South African young adult population were normally distributed. The mean CCT and minimum corneal thickness measurements in this study were lower than the values reported in other studies involving young adult samples globally. No clinically significant gender related differences in corneal thickness measurements were observed. The values presented in this study are suitable for clinical use as they are representative of a healthy South African young adult population and may provide a foundation for the interpretation of patients' clinical data with more confidence. Moreover, knowledge of the distribution, mean values and characteristics of corneal thickness measurements in a specific population of young adults of a similar age range allows for future studies to be conducted without the need for a control group. ${ }^{33,35}$ It is suggested that optometrists and ophthalmologists utilise the information herein when considering the distribution, means, medians and other characteristics of corneal thickness measurements when examining South African individuals.

\section{Acknowledgements}

The authors acknowledge Prof. C.P. Brown from the Florida Agricultural and Mechanical University for assistance with the statistical analysis. At the time of this study, Prof. Brown was assisting with statistical guidance at the University of KwaZulu-Natal.

\section{Competing interests}

The authors declare that they have no financial or personal relationships that may have inappropriately influenced them in writing this article.

\section{Authors' contributions}

N.R. wrote the manuscript and R.H. provided feedback on the structure and content of the manuscript.

\section{References}

1. Sutton GL, Kim P. Laser in situ keratomileusis in 2010 - A review. Clin Experiment Ophthalmol. 2010;38:192-210. https://doi.org/10.1111/j.1442-9071.2010.02227.x

2. Myrowitz EH, Melia M, O' Brien TP. The relationship between long-term contact lens wear and corneal thickness. CLAO J. 2002;28:217-220.

3. Saad A, Gatinel D. Topographic and tomographic properties of forme fruste keratoconus corneas. Invest Ophthalmol Vis Sci. 2010;51:5546-5555. https://doi. org/10.1167/iovs.10-5369

4. Kohlhaas M, Boehm AG, Spoerl E, Pürsten A, Grein HJ, Pillunat LE. Effect of central corneal thickness, corneal curvature, and axial length on applanation tonometry. Arch Ophthalmol. 2006;124:471-476. https://doi.org/10.1001/archopht.124.4.471

5. Hahn S, Azen S, Ying-Lai M, Varma R. Central corneal thickness in Latinos. Investigative Ophthalmol Vis Sci. 2003;44:1508-1512. https://doi.org/10.1167/ iovs.02-0641

6. Khoramnia R, Rabsilber TM, Auffarth GU. Central and peripheral pachymetry measurements according to age using the Pentacam rotating Scheimpflug camera. J Cataract Refract Surg. 2007;33:830-836. https://doi.org/10.1016/j.jcrs.2006. 12.025

7. Mohan S, Aggarwal A, Dada T, Vanathi M, Panda A. Pachymetry: A review. DOS Times. 2007;12:19-28.

8. Huang J, Liao N, Savini G, et al. Measurement of central corneal thickness with optical low coherence reflectometry and ultrasound pachymetry in normal and post-femtosecond laser in situ keratomileusis eyes. Cornea. 2015;34:204-208. https://doi.org/10.1097/ICO.0000000000000329

9. Nam SM, Im CY, Lee HK, Kim EK, Kim TI, Seo KY. Accuracy of RTVue optical coherence tomography, Pentacam, and ultrasonic pachymetry for the measurement of central corneal thickness. Ophthalmology. 2010;117:2096-2103. https://doi. org/10.1016/j.ophtha.2010.03.002

10. Módis L, Szalai E, Németh G, Berta A. Reliability of the corneal thickness measurements with the Pentacam HR imaging system and ultrasound pachymetry Cornea. 2011;30:561-566. https://doi.org/10.1097/ICO.0b013e318200096a

11. Fares U, Otri AM, Al-Aqaba MA, Dua HS. Correlation of central and peripheral corneal thickness in healthy corneas. Cont Lens Anterior Eye. 2012;35:39-45. https://doi.org/10.1016/j.clae.2011.07.004 
12. Huang D, Swanson EA, Lin CP, et al. Optical coherence tomography. Science. 1991;254:1178-1181. https://doi.org/10.1126/science.1957169

13. Fujimoto JG. Optical coherence tomography for ultrahigh resolution in vivo imaging. Nat Biotechnol. 2003;21:1361-1367. https://doi.org/10.1038/nbt892

14. Hirano K, Ito Y, Suzuki T, Kojima T, Kachi S, Miyake Y. Optical coherence tomography for the noninvasive evaluation of the cornea. Cornea. 2001;20:281-289. https:// doi.org/10.1097/00003226-200104000-00009

15. Izatt JA, Hee MR, Swanson EA, et al. Micrometer-scale resolution imaging of the anterior eye in vivo with optical coherence tomography. Arch Ophthalmol. 1994;112:1584-1589. https://doi.org/10.1001/archopht.1994.01090240090031

16. Ramos JLB, Li Y, Huang D. Clinical and research applications of anterior segment optical coherence tomography - A review. Clin Experiment Ophthalmol.2009;37:81-89. https://doi.org/10.1111/j.1442-9071.2008.01823.x

17. Randleman JB, Lynn MJ, Perez-Straziota CE, Weissman HM, Kim SW. Comparison of central and peripheral corneal thickness measurements with scanning-slit, Scheimpflug and Fourier-domain ocular coherence tomography. Br J Ophth

18. Li Y, Shekhar R, Huang D. Corneal pachymetry mapping with high-speed optical coherence tomography. Ophthalmology. 2006;113:792-799. https://doi. org/10.1016/j.ophtha.2006.01.048

19. Zhang $\mathrm{H}, \mathrm{Xu} \mathrm{L}$, Chen C, Jonas JB. Central corneal thickness in adult Chinese. Associations with ocular and general parameters. The Beijing Eye Study. Graefes Arch Clin Exp Ophthalmol. 2008;246:587-592. https://doi.org/10.1007/s00417Arch Clin Exp

20. Yuen LH, He M, Aung T, Htoon HM, Tan DT, Mehta JS. Biometry of the cornea and the anterior chamber in Chinese eyes: An anterior segment optical coherence tomography study. Invest Ophthalmol Vis Sci. 2010;51:3433-3440. https://doi. tomography study. Invest
org/10.1167/iovs.09-4307

21. Ang M, Chong W, Tay WT, et al. Anterior segment optical coherence tomography study of the cornea and anterior segment in adult ethnic South Asian Indian eyes. Invest Ophthalmol Vis Sci. 2012;53:120-125. https://doi.org/10.1167/iovs.118386

22. Keech $A$, Simpson $T$, Jones $L$. Repeatability of pachymetry and thinnest point localization using a Fourier-domain optical coherence tomographer. Optom Vis Sci. 2010;87:736-741. https://doi.org/10.1097/OPX.0b013e3181f321aa

23. Mohamed S, Lee GKY, Rao SK, et al. Repeatability and reproducibility of pachymetric mapping with Visante anterior segment - Optical coherence tomography. Invest Ophthalmol Vis Sci. 2007;48:5499-5504. https://doi. org/10.1167/iovs.07-0591

24. Huang JY, Pekmezci M, Yaplee S, Lin S. Intra-examiner repeatability and agreement of corneal pachymetry map measurement by time-domain and Fourier-domain optical coherence tomography. Graefes Arch Clin Exp Ophthalmol. 2010;248:1647-1656. https://doi.org/10.1007/s00417-010-1360-7

25. Ishibazawa A, Igarashi S, Hanada K, et al. Central corneal thickness measurements with Fourier-domain optical coherence tomography versus ultrasonic pachymetry and rotating Scheimpflug camera. Cornea. 2011;30:615-619. https://doi.org/ 10.1097/ICO.0b013e3181d00800

26. Wolfs RCW, Klaver CCW, Vingerling JR, Grobbee DE, Hofman A, de Jong PTVM Distribution of central corneal thickness and its association with intraocula pressure: The Rotterdam Study. Am J Ophthalmol. 1997;123:767-772. https:// doi.org/10.1016/S0002-9394(14)71125-0

27. Gros-Otero J, Arruabarrena-Sánchez C, Teus M. Central corneal thickness in healthy Spanish population. Arch Soc Esp Oftalmol. 2011;86:73-76. https://doi. org/10.1016/j.oftal.2010.12.008

28. Foster PJ, Baasanhu J, Alsbirk PH, Munkhbayar D, Uranchimeg D, Johnson GFJ. Central corneal thickness and intraocular pressure in a Mongolian population. Ophthalmology 1998;105:969-973. https://doi.org/10.1016/S0161-6420(98)96021-3

29. Zheng Y, Huang G, Huang W, He M. Distribution of central and peripheral corneal thickness in Chinese children and adults: The Guangzhou Twin Eye Study. Cornea. 2008;27:776-781. https://doi.org/10.1097/ICO.0b013e31816f62d3

30. Hwang YH, Kim HK, Sohn YH. Central corneal thickness in a Korean population: The Namil Study. Invest Ophthalmol Vis Sci. 2012;53:6851-6855. https://doi. org/10.1167/iovs.12-10173

31. Aghaian E, Choe JE, Lin S, Stamper RL. Central corneal thickness of Caucasians, Chinese, Hispanics, Filipinos, African Americans, and Japanese in a glaucoma

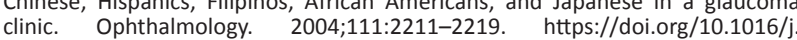
clinic. Ophthalmol
ophtha.2004.06.013

32. Brandt JD, Beiser JA, Kass MA, Gordon MO. Central corneal thickness in the Ocula Hypertension Treatment Study (OHTS). Ophthalmology. 2001;108:1779-1788. https://doi.org/10.1016/S0161-6420(01)00760-6

33. Doughty MJ, Zaman ML. Human corneal thickness and its impact on intraocular pressure measures: A review and meta-analysis approach. Surv Ophthalmol. 2000;44:367-408. https://doi.org/10.1016/S0039-6257(00)00110-7

34. Fam HB, Lim KL, Reinstein DZ. Orbscan global pachymetry: Analysis of repeated measures. Optom Vis Sci. 2005;82:1047-1053. https://doi.org/10.1097/01. opx.0000192348.37026.09

35. Hashemi H, Yazdani K, Mehravaran S, et al. Corneal thickness in a populationbased, cross-sectional study: The Tehran Eye Study. Cornea. 2009;28:395-400. https://doi.org/10.1097/ICO.0b013e31818c4d62

36. Tai LY, Khaw KW, Ng CM, Subrayan V. Central corneal thickness measurements with different imaging devices and ultrasound pachymetry. Cornea. 2013;32:766-771. https://doi.org/10.1097/ICO.0b013e318269938d

37. Dimasi DP, Burdon KP, Craig JE. The genetics of central corneal thickness. $\mathrm{Br}$ Ophthalmol. 2010;94:971-976. https://doi.org/10.1136/bjo.2009.162735
38. Sardiwalla Z, Moodley D, Ndawonde T, et al. A comparative study of central corneal thickness (CCT) and intraocular pressure (IOP) in University of KwaZuluNatal students of Black and Indian ethnicity. S Afr Optom. 2012;71:171-177. Natal students of Black and Indian ethn
https://doi.org/10.4102/aveh.v71i4.83

39. Stephens GL. Correction with single-vision spectacle lenses. In: Benjamin WJ, editor. Borish's clinical refraction. 2nd ed. St. Louis, MO: Butterworth Heinemann, 2006; p. 1026-1094.

40. Optovue Inc. iVue 100 user's manual version 1.9. Fremont, CA: Optovue Inc.; 2011.

41. Read SA, Collins MJ. Diurnal variation of corneal shape and thickness. Optom Vis Sci. 2009;86:170-180. https://doi.org/10.1097/OPX.0b013e3181981b7e

42. Mashige KP, Rampersad, N, Jhetam S, Govender P. Short-term variation in central corneal thickness and intraocular pressure using the tonopachymeter NT530P tonpachymeter (TonopachyTM). S Afr Optom. 2012;71:12-21.

43. Rüfer F, Sander S, Klettner A, Frimpong-Boateng A, Erb C. Characterization of the thinnest point of the cornea compared with the central corneal thickness in normal subjects. Cornea. 2009;28:177-180. https://doi.org/10.1097/ICO.0b013e 3181861c29

44. Armstrong RA. Statistical guidelines for the analysis of data obtained from one or both eyes. Ophthalmic Physiol Opt. 2013;33:7-14. https://doi.org/10.1111/ opo.12009

45. Hashemi $\mathrm{H}$, Asgari $\mathrm{S}$, Mehravaran $\mathrm{S}$, Emamian $\mathrm{MH}$, Shariati M, Fotouhi $\mathrm{A}$. The distribution of corneal thickness in a 40-to 64-year-old population of Shahroud, Iran. Cornea. 2011:30:1409-1413. https://doi.org/10.1097//CO.0b013e318220 Iran.

46. Graeber CPT, M B, Shields MB. Central corneal thickness in a Puerto Rican population. J Glaucoma. 2008;17:356-360. https://doi.org/10.1097/IJG.0b013e $31815 c 5 f 15$

47. Herse $P$, Yao W. Variation of corneal thickness with age in young New Zealanders. Acta Ophthalmol. 1993;71:360-364. https://doi.org/10.1111/j.1755-3768.1993. tb07148.x

48. Prakash G, Kumar DA, Agarwal A, Sarvanan Y, Jacob S, Agarwal A. Evaluation of bilateral minimum thickness of normal corneas based on Fourier-domain optical coherence tomography. J Cataract Refract Surg. 2010;36:1365-1372. https://doi. org/10.1016/j.jcrs.2010.02.023

49. Bland JM, Altman DG. Statistical notes: Transforming data. Br Med J. 1996;312:770 https://doi.org/10.1136/bmj.312.7033.770

50. Bland JM. The normal distribution. In: An introduction to medical statistics. 4th ed. New York: Oxford University Press, 2015; p. 85-100.

51. Li Y, Bao FJ. Interocular symmetry analysis of bilateral eyes. J Med Eng Technol. 2014;38:179-187. https://doi.org/10.3109/03091902.2014.899401

52. Sanchis-Gimeno JA, Lleó-Pérez A, Alonso L, Rahhal MS, Martínez-Soriano F. Anatomic study of the corneal thickness of young emmetropic subjects. Cornea. 2004;23:669-673. https://doi.org/10.1097/01.ico.0000126323.20767.89

53. Li P, Hu Y, Xu Q, Zhang G, Mai C. Central corneal thickness in adult Chinese. J Huazhong Univ Sci Technolog Med Sci. 2006;26:141-144. https://doi.org/10. 1007/BF02828062

54. Cho P, Lam C. Factors affecting the central corneal thickness of Hong KongChinese. Curr Eye Res. 1999;18:368-374. https://doi.org/10.1076/ceyr.18.5. 368.5347

55. Mohd-Ali B, Ching HO, Latif NAA. Corneal thickness and curvature of one sample of young myopic population in Malaysia. Malays J Health Sci. 2009;7:49-58.

56. Whitacre MM, Stein RA, Hassanein K. The effect of corneal thickness on applanation tonometry. Am J Ophthalmol 1993;115:592-596. https://doi org/10.1016/S0002-9394(14)71455-2

57. Khairat YM, Mohamed YH, Moftah IANO, Fouad NN. Evaluation of corneal changes after myopic LASIK using the Pentacam. Clin Ophthalmol. 2013;7:1771-1776.

58. Eballe AO, Koki G, Ellong $A$, et al. Central corneal thickness and intraocular pressure in the Cameroonian nonglaucomatous population. Clin Ophthalmol. 2010;4:717-724. https://doi.org/10.2147/OPTH.S10575

59. Durkin SR, Tan EWH, Casson RJ, Selva D, Newland HS. Central corneal thickness among Aboriginal people attending eye clinics in remote South Australia. Clin Experiment Ophthalmol. 2007;35:728-732. https://doi.org/10.1111/j.1442-9071. 2007.01574.x

60. Módis Jr L, Langenbucher A, Seitz B. Evaluation of normal corneas using scanningslit topography/pachymetry system. Cornea. 2004;23:689-694. https://doi.org/ 10.1097/01.ico.0000126315.05519.0b

61. Hussein MAW, Paysse EA, Bell NP, et al. Corneal thickness in children Am J Ophthalmol. 2004;138:744-748. https://doi.org/10.1016/j.ajo.2004.06.030

62. Henriksson JT, Bron AJ, Bergmanson JPG. An explanation for the central to peripheral thickness variation in the mouse cornea. Clin Experiment Ophthalmol. 2012;40:174-181. https://doi.org/10.1111/j.1442-9071.2011.02652.x

63. Tao A, Wang J, Chen $Q$, et al. Topographic thickness of Bowman's layer determined by ultra-high resolution spectral domain-optical coherence tomography. Invest Ophthalmol Vis Sci. 2011;52:3901-3907. https://doi.org/10.1167/iovs.09-4748

64. Rüfer F, Schröder A, Bader C, Erb C. Age-related changes in central and peripheral corneal thickness: Determination of normal values with the Orbscan II topography system. Cornea. 2007;26:1-5. https://doi.org/10.1097/ 01.ico.0000240095.95067.3f

65. Huang J, Ding X, Savini G, et al. Central and midperipheral corneal thickness measured with Scheimpflug imaging and optical coherence tomography. PLoS One [serial online]. 2014 [cited 2017 May 26];9(5). Available from: http://journals. plos.org/plosone/article?id=10.1371/journal. pone.0098316 
66. Erickson P, Comstock TL, Zantos SG. Is the superior cornea continuously swollen? Clin Exp Optom. 2002;85:168-171. https://doi.org/10.1111/j.1444-0938.2002.tb03030.x

67. Ashwin PT, Shah S, Pushpoth S, Wehbeh L, Ilango B. The relationship of central corneal thickness (CCT) to thinnest central cornea (TCC) in healthy adults. Cont Lens Anterior Eye. 2009;32:64-67. https://doi.org/10.1016/j.clae.2008.07.006

68. Demirbas NH, Pflugfelder SC. Topographic pattern and apex location of keratoconus on elevation topography maps. Cornea. 1998;17:476-484. https:// doi.org/10.1097/00003226-199809000-00004

69. Malecaze F, Coullet J, Calvas P, Fournié P, Arné J, Brodaty C. Corneal ectasia after photorefractive keratectomy for low myopia. Ophthalmology. 2006;113:742-746. https://doi.org/10.1016/j.ophtha.2005.11.023
70. Cosar CB, Sener AB. Orbscan corneal topography system in evaluating the anterior structures of the human eye. Cornea. 2003;22:118-121. https://doi.org/10.1097/ 00003226-200303000-00007

71. Mohamed NY, Hassan MN, Ali NAM, Binnawi KH. Central corneal thickness in Sudanese population. Sud J Ophthalmol. 2009;1:29-32.

72. Mostafa EM. Central corneal thickness in southern Egypt. Int Ophthalmol. 2014;34:809-815. https://doi.org/10.1007/s10792-013-9885-5

73. Nakhjavanpour N, Payandeh A, Rajabi M, Shoja V. Anterior segment eye assessment of refractive surgery candidates in the southeast of Iran. Global J Health Sci. 2016;8:133-140. https://doi.org/10.5539/gjhs.v8n12p133 